\title{
AS REPRESENTAÇÕES SEM CONSCIÊNCIA EM KANT
}

\author{
Representations without conscience in Kant
}

Luís Eduardo Ramos de Souza

UFPA

Aline Brasiliense dos Santos Brito

UFPA

Resumo: Kant desenvolve o tema das representações sem consciência, obscuras e inconscientes de forma fragmentária e dispersa ao longo das suas obras. Por essa razão, este trabalho tem por objetivo, primeiramente, identificar e agrupar diversas passagens em que Kant trata desta matéria em vários dos seus textos, e, posteriormente, analisar e relacionar suas ideias a fim de formar uma visão global e articulada acerca desta classe especial de representações. As posições defendidas neste texto são as seguintes: primeira, indicar que Kant compreende as representações sem consciência em sentido próximo ao das representações não conscientes; segunda, mostrar que as representações sem consciência (ou não conscientes) constituem o gênero mais amplo sob o qual estão contidas as representações obscuras e inconscientes; terceira, argumentar que estas duas espécies de representações sem consciência não são definidas de modo absoluto, mas em relação à noção de graus e de déficits de atenção, respectivamente; quarta, propor que as representações sem consciência em Kant podem ser denominadas de percepções obscuras ou indistintas, em oposição às representações com consciências, as quais podem ser designadas como percepções claras ou distintas.

Palavras-chaves: consciência. Inconsciente. Kant. Representations

Abstract: Kant develops the theme of representations without consciousness, obscure and unconscious in a fragmentary and scattered manner throughout their works. Therefore, this paper aims initially identify and group several passages in which Kant deals of this matter in several of his texts, and posteriorly analyze and relate their ideas to form a comprehensive and articulated vision about this class special of representations. The views expressed in this paper are as follows: first, indicate that Kant understands the representations without consciousness in sense close to the no conscious representations; second, to show that the representations without consciousness (or no conscious) constitute the broader genre in which are contained the obscure and unconscious representations; third, argue that these two kinds of representations without consciousness are not defined in absolute terms, but in relation to the notion of degrees and attention deficits, respectively; fourth, propose that the representations without consciousness in Kant can be called obscure or indistinct perceptions, while opposed to representations with consciousness, which can be designated as clear or distinct perceptions.

Keywords: consciousness. Obscure. Unconscious. Kant. Representations 


\section{1. $O$ ponto de partida de Kant: a representação em geral ${ }^{1}$}

Em uma passagem da CRPu (B376-7), Kant desenvolve uma breve reflexão sobre o conceito de representação, cujo intuito é fornecer uma classificação geral das representações. Para isso, ele parte do conceito mais extenso, a saber, a classe ou o gênero superior da 'representação em geral' (Vorstellung überhaupt). A partir daí, ele apresenta apenas um único ramo da divisão deste conceito geral e se ocupa exclusivamente das suas partições. A este ramo ele denomina de 'representações com consciência' (Vorstellungen mit Bewusstsein). Naturalmente, a partir deste fato, surge a seguinte questão: qual seria, então, o outro ramo da 'representação em geral' não tratado sistematicamente por Kant nesta (e talvez em nenhuma outra) passagem? A suposição óbvia é a de que este ramo tácito se refere às representações opostas àquelas mencionadas por ele, a saber, as 'representações sem consciência' (Vorstellungen ohne Bewusstsein).

Portanto, ao tratar explicitamente das representações com consciência (mit Bewusstsein), Kant remete implicitamente em suas obras a outra forma de representações: aquelas sem consciência (ohne Bewusstsein). Em suas palavras: "o gênero e a representação em geral (...), sob ela está a representação com consciência" (B376, itálico acrescentado). A respeito desta classificação, V. Rohden comenta que “(...) sob as representações em geral poderia supor-se um segundo grupo, o das representações sem consciência (...)", isto porque - continua ele - segundo a escala de Kant, "todas as demais representações que se seguem são especificações desta representação com consciência" (2009, p. 3). Na verdade, Kant desenvolve nesta passagem tão somente as divisões relativas às representações com consciência, deixando completamente de lado as referidas divisões quanto às representações sem consciência.

\footnotetext{
${ }^{1}$ Serão usadas as seguintes abreviações das obras de Kant: Refl. para as Reflexões antropológicas; CRPu para Crítica da razão pura; CFJ para Crítica da faculdade do juízo; Antr., para Antropologia de um ponto de vista pragmático; Lóg. para o Manual dos cursos de Lógica; Religião, para a Religião nos limites da simples razão e DV para a Doutrina da virtude.
} 
Esquematicamente, nesta passagem, tem-se a seguinte visão de Kant acerca da representação em geral, segundo a sua divisão em representação com consciência e sem consciência:

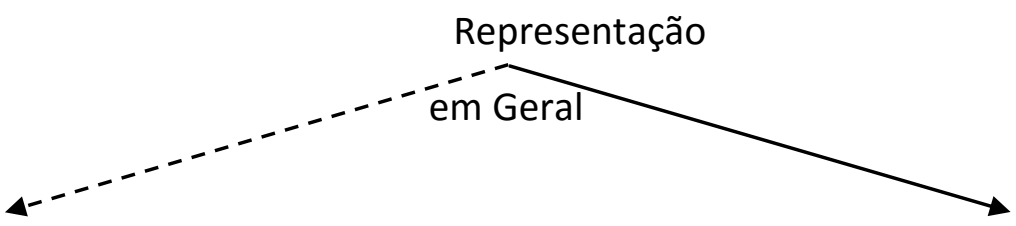

\author{
Representação \\ sem Consciência

\begin{abstract}
A linha cheia indica a divisão explícita de Kant quanto à representação com consciência, e a linha tracejada a sua divisão implícita quanto à representação sem consciência.
\end{abstract}

Representação

com Consciência

De fato, o assunto é inúmeras vezes inserido, sempre fugidiamente, na CRPu, tal como, por exemplo, pode-se ver nas seguintes passagens: “(...) toda ligação - quer sejamos dela conscientes ou não (...) - é um ato do entendimento (...)" (CRPu, B130); “(...) Há incontáveis graus de consciência, portanto até seu desaparecimento" (CRPu, B415); "tudo, no entanto, e mesmo toda representação, na medida em que se é dela consciente, pode ser denominado objeto" (CRPu, B235) ${ }^{2}$.

O fato é que as representações sem consciência constituem um tema abordado por Kant não somente na $C R P u$, mas tem o seu registro já desde o período pré-crítico de forma sempre espargida. Por exemplo, nos Sonhos de um visionário (1766), Kant escreve: “(...) muitos conceitos nascem de conclusões ocultas e obscuras por ocasião das experiências e se transferem depois para outros sem a consciência da própria experiência ou da conclusão que fundou o conceito sobre ela. (...) Há muitos deles, que em parte nada mais são do que uma ilusão da imaginação, e em parte também são verdadeiros, na medida em que mesmo conclusões obscuras nem sempre

\footnotetext{
${ }^{2}$ Os itálicos destas citações foram acrescentados pelos autores.
} 
erram (...)" (II 320) ${ }^{3}$. Também nas Reflexões Kant trata da existência de representações obscuras (Rohden, 2009).

\section{Classificação geral das representações sem consciência: espécie e domínio}

Embora Kant não efetue uma classificação explícita das representações sem consciência, não obstante, ao se reunirem os trechos em que se refere ao assunto, pode-se notar que existem representações sem consciência no domínio teórico, prático e estético, além das que Kant reserva especificamente para o caso da sensação. Esta compreensão é também compartilhada por Allison, embora o reconheça parcialmente apenas nos dois primeiros campos, ao afirmar que "apesar de que Kant não desenvolve este tema na $C R P u$, veremos que está em total disposição admitir representações inconscientes capazes de influenciar nossos desejos e sentimentos (1992, p. 225)"'4.

Além disso, pode-se observar que, no ramo (gênero) das representações sem consciência, Kant inclui duas espécies principais de representações, a saber: as obscuras e as inconscientes. No fundo, todas as representações sem consciência analisadas por Kant recaem sob uma destas duas espécies, as quais são refletidas no campo teórico, prático ou estético. O quadro abaixo resume estas informações preliminares sobre as espécies e os domínios das representações sem consciência:

\begin{tabular}{|c|c|c|c|}
\hline & \multicolumn{3}{|c|}{ REPRESENTAÇÕES SEM CONSCIÊNCIA } \\
\hline & \multicolumn{3}{|c|}{ Obscuro } \\
\hline ESPECIES & \multicolumn{3}{|c|}{ Inconsciente } \\
\hline DOMÍNIOS & Teórico & Prático & Estético \\
\hline
\end{tabular}

As representações sem consciência possuem duas espécies principais (obscuro, inconsciente) e três domínios (teórico, prático, estético).

\footnotetext{
${ }^{3}$ Itálicos acrescentados pelos autores.

${ }^{4} \mathrm{Na}$ edição inglesa expandida do mesmo livro, Allison escreve nesta passagem: "O eu é aqui o sujeito cognitivo concebido abstratamente, não um sujeito real, empiricamente, com sonhos, desejos, volições (ambos conscientes ou inconscientes [unconscious])" (2004, p. 164).
} 
Em linhas gerais, pode-se dizer que há as seguintes relações entre as espécies e os domínios das representações sem consciência. Primeiro, para Kant, o domínio das representações sem consciência é idêntico ao das representações com consciência, uma vez que ambas tem como escopo o domínio teórico, prático e estético. Segundo, Kant considera o gênero das representações sem consciência como idêntico ao das representações não conscientes. Terceiro, ele distingue no gênero das representações sem consciência (ou não conscientes) as espécies do obscuro e do inconsciente. Quarto, ele diferencia estas duas espécies de modo regular ao definir o obscuro mediante o conceito de grau e o inconsciente mediante o conceito de déficit de atenção, embora seus conceitos sejam aproximáveis. As justificativas e esclarecimentos destes pontos são encontrados nos próximos tópicos.

(Para uma visão mais ampla de todas as classificações, feita por Kant, acerca da representação em geral - com e sem consciência - pode-se consultar o Apêndice A).

\section{Esclarecimento terminológico sobre as representações sem consciência}

Para a compreensão do sentido e da função de tais representações na filosofia de Kant é imprescindível, primeiramente, destacar o que significa para ele este gênero de representações sem consciência, e como também emprega os termos 'não consciente', 'obscuro' e 'inconsciente'. Há uma relação geral de aproximação e distinção entre tais termos, de tal maneira que para esclarecer a matéria torna-se essencial o recurso aos termos originais em alemão.

Naturalmente, o conceito central a ser aqui focalizado é o gênero da representação sem consciência, a qual é concebida por Kant como um gênero de representações contraposto ao da representação com consciência, sendo ambas derivadas do gênero superior da representação em geral.

Em linhas gerais, pode-se dizer que há uma aproximação maior entre o significado dos termos 'sem consciência' e 'não consciente', bem como uma 
determinação, a partir destes, do significado dos termos 'obscuro' e 'inconsciente', além de aproximações conceituais entre estas duas últimas expressões.

Primeiramente, para o termo 'não consciente' Kant usa a expressão alemã nicht bewusst, cujo sentido geral equivale ao próprio gênero das representações sem consciência (ohne Bewusstsein), descrito acima, sendo, portanto, ambos opostos às representações com consciência ou conscientes.

Já o 'inconsciente' é empregado por ele através de duas expressões alemãs diferentes: o unbewusst, que é empregado como adjetivo e em nenhum momento como substantivo, e o Gewissenlos e Gewissenlosigkeit, que são substantivos usados em uma acepção moral.

De um lado, o termo 'inconsciente' (em alemão, unbewusst) ocorre com menos frequência na obra de Kant que o 'não consciente' e o 'obscuro', e nesta acepção, convém notar que o 'inconsciente' (unbewusst) vincula-se ao estado do sujeito, ao passo que o 'não consciente' (nicht bewusst) é referido ao gênero de representações. Em outras palavras, para distinguir o gênero da representação, Kant emprega o 'não consciente' (nicht bewusst), e para discernir sobre o estado do sujeito com relação a estas representações, Kant utiliza-se do termo 'inconsciente' (unbewusst). O unbewusst nunca é usado como substantivo e sugere um estado passageiro de desaparecimento da consciência (como bem aponta o trecho da Lógica que será discutido à frente), isto é, denota um estado, uma qualidade momentânea do sujeito, ao qual Kant vincula o conceito de atenção, no sentido de que somos momentaneamente inconscientes quando não voltamos a atenção para algo, isto é, quando ocorre um déficit de atenção por parte do sujeito. Por outro lado, a ocorrência do termo 'inconsciente', na forma de um substantivo (em alemão, Gewissenlos e Gewissenlosigkeit), aparece no sentido de uma espécie de inconsciência moral, cujo uso é bem mais frequente nos textos de Kant, tal como pode ser constatado na Religião nos limites da simples razão (1793) e na Metafísica dos costumes - Doutrina da virtude (1797). 
Por fim, o termo 'obscuro' aparece em Kant mediante o uso da expressão alemã Dunkel (substantivo) e dunkel (adjetivo). De modo geral, Kant compreende o termo 'obscuro' no sentido de um grau de consciência, isto é, enquanto uma forma de consciência muito fraca, pouco significativa, mas sem implicar um completo desaparecimento da mesma - quer dizer, sem que este grau de consciência assuma o valor zero de modo absoluto.

\section{Aproximação entre as representações sem consciência e as não conscientes}

A primeira parte da tese deste trabalho consiste em justificar que, em Kant, o gênero da representação sem consciência (ohne Bewusstsein) tem um sentido próximo ao da representação não consciente (nicht bewusst).

De fato, nestas duas expressões os termos "sem" e "não" que nelas aparecem podem indicar uma diferenciação entre ambas, na medida em que o primeiro qualifica algo temporário, e o segundo algo estável. Todavia, convém notar que Kant não leva em conta, de um modo geral, esta sutil diferenciação terminológica, pois ele utiliza com frequência a expressão 'não consciente' de modo amplo e livre para se referir ou qualificar as duas espécies de representações sem consciência (isto é, o obscuro e o inconsciente). Isto indica que ele compreende tanto as representações não conscientes quanto as representações sem consciência enquanto o mesmo gênero que contém como espécies as representações obscuras e inconscientes.

Para corroborar este ponto de vista, há duas passagens que podem ser citadas. A primeira, na Antropologia (Ak135), quando Kant caracteriza as representações obscuras (dunkelen) como aquelas "de que não somos imediatamente conscientes". A segunda, na Lógica (Ak11), quando ele qualifica as representações inconscientes (unbewussten) como aquelas de que se faz uso "segundo regras de que não tem consciência". Nestes dois exemplos, Kant admite que tanto as representações obscuras como as inconscientes sejam espécies contidas no gênero das representações não conscientes. 
Neste sentido, é justificável dizer que ele considera praticamente como sinônimas ou equivalentes as representações sem consciência (ohne Bewusstsein) e as representações não conscientes (nicht bewussten), as quais são, por sua vez, identificadas ao gênero que forma o ramo contraposto ao das representações com consciência ou conscientes. Apesar da diferença terminológica entre tais expressões, pode-se afirmar, no entanto, que não há distinção semântica relevante entre ambas, no sentido aqui indicado.

\section{As representações obscuras}

Historicamente, a noção do obscuro já aparece nos filósofos anteriores a Kant, não enquanto um conceito, propriamente dito, mas enquanto uma espécie de metáfora, constituindo o que pode ser chamado de a 'metáfora da obscuridade' (GÖDDE, 1999). Por exemplo, em Descartes, o obscuro aparece como aquilo (juízo, percepção) que é da ordem do duvidoso, em oposição àquilo que é claro e distinto ${ }^{5}$. Em Leibniz, como as percepções mínimas e inapercebidas das Mônadas ${ }^{6}$.

Em particular, Leibniz usa explicitamente a noção de obscuro em seus Novos ensaios sobre o entendimento humano (1764), no qual o obscuro é caracterizado como percepções confusas presentes em todo momento na alma humana:

(...) Existe a todo momento uma infinidade de percepções em nós, porém sem a percepção e sem reflexão: mudanças na própria alma, das quais não nos apercebemos, pelo fato de as impressões serem ou muito insignificantes e em número muito elevado, ou muito unidas, de sorte que não apresentam isoladamente nada de suficientemente distintivo: porém, associadas a outras, não deixam de produzir o seu efeito e de fazer-se sentir ao menos confusamente (1764, p. 11).

\footnotetext{
${ }^{5}$ Ver Descartes, Princípios da filosofia, em particular os $\S \S 45,46$ e 47.

${ }^{6}$ Leibniz tem uma visão positiva do obscuro, considerando que a claridade surge a partir de processos obscuros, contrariamente à escala claro-distinto-obscuro apresentada por Descartes, que privilegia as duas primeiras gradações. A esse respeito comenta Deleuze em A dobra: Leibniz e o barroco (1991, p. 153): "Ao contrário de Descartes, Leibniz parte do obscuro: é que o claro sai do obscuro por um processo genético. Outrossim, o claro imerge no obscuro e não para de nele imergir: ele é claro-obscuro por natureza, é desenvolvimento do obscuro, é mais ou menos claro, tal como o sensível o revela (...)".
} 
No caso de Kant, é possível encontrarem-se em seu pensamento diversos esclarecimentos acerca desta noção, de tal modo que, ao reuni-las, pode-se dizer que Kant não tem apenas uma simples metáfora acerca do obscuro, mas sim um conceito definido precisamente em dois sentidos distintos (grau e déficit de atenção) e aplicado em três domínios diferentes (teórico, prático e estético).

\section{a) Os graus da obscuridade}

Por um lado, Kant compreende a representação obscura no sentido de um grau que determina o conceito de consciência, na medida em que ele emprega aí a noção de grau de consciência ${ }^{7}$. Em linhas gerais, isso significa que a consciência de algo pode variar o grau da sua intensidade de modo contínuo e infinito dentro de uma escala compreendida entre 0 e 1. Segundo ele, toda consciência possui um grau, "pois mesmo a consciência, portanto a faculdade de ser consciente de si mesmo, e assim todas as demais faculdades tem sempre um grau que pode ser ainda diminuído" (CRPu, B414). Na Lógica (Ak35) ele escreve: “(...) a indistinção repousa (...) sobre a debilidade da consciência (...), a distinção pode diminuir (...) se o grau de consciência decresce (...)".

Embora os graus de consciência possam, em princípio, variar contínua e infinitamente na escala de 0-1, Kant distingue, todavia, três graus de consciência fundamentais, a saber: a distinção, a clareza e o obscuro. Esta tríplice divisão dos graus de consciência pode ser, por sua vez, aplicada, no domínio teórico, às representações intelectuais e estéticas, isto é, aos conceitos e às intuições sensíveis ${ }^{8}$.

O primeiro grau de consciência - a distinção (Deutlichkeit) - é uma representação que se refere a uma consciência clara de nível mais elevado, que consiste na clareza das partes contidas em uma representação, constituindo uma espécie de análise. O segundo grau de consciência - a clareza (Klarheit) - é uma

\footnotetext{
${ }^{7} \mathrm{~A}$ noção de grau é aplicada por Kant também a outros conceitos, além do de consciência, como por exemplo, o de sensação (CRPu, B207ss.), o de faculdade e do eu (CRPu, B414-5).

${ }^{8} \mathrm{Na}$ verdade, dito de modo mais amplo, esta tríplice divisão dos graus de consciência se aplica a todos os domínios: teórico, prático e estético.
} 
representação que tem a ver com a consciência que percebe a simples diferença entre um objeto e outro, sem, porém, distinguir as suas partes constituintes - isto é, tal como esclarece Kant, "a consciência das próprias representações que basta para diferenciar um objeto de outro é a clareza" (Antr., Ak138). Kant oferece o seguinte exemplo para compreender os graus da clareza e da distinção estética (sensível):

Vejo, por exemplo, a via láctea como uma faixa esbranquiçada. Os raios luminosos de cada uma das estrelas individuais que nela se encontram devem ter chegado necessariamente até meu olho. Mas sua representação foi apenas clara e só pelo telescópio se torna distinta, porque agora vejo as estrelas individuais contidas naquela faixa esbranquiçada (Lóg., Ak35).

O terceiro e último grau de consciência - o obscuro (Dunkel) - é uma representação definida, por Kant, mediante duas notas completares: de um lado, o obscuro tem um grau de consciência muito fraco, devido a uma limitação - isto é, a diminuição do grau - de uma das faculdades do sujeito (memória, atenção, linguagem, sentidos, conceitos); de outro, devido a tal limitação do grau de consciência, o obscuro é percebido de forma mediata ou indireta, através das representações claras ou distintas.

O primeiro aspecto da definição da representação obscura pode ser explicado por Kant através do exemplo do enfraquecimento da faculdade da memória:

(...) Um certo grau de clareza que não baste para a rememoração pode ser encontrado até mesmo em muitas representações obscuras, já que sem consciência alguma nós não faríamos qualquer distinção na ligação de representações obscuras, e isto é algo que conseguimos fazer quanto a característica de muitos conceitos (como aqueles do direito e da equidade, ou do músico que, no fantasiar, compreende muitas notas ao mesmo tempo) (...). Há incontáveis graus de consciência, portanto até seu desaparecimento (CRPu, B415, itálicos acrescentados).

Nesta passagem, fica evidente que Kant compreende o obscuro enquanto um grau de consciência muito fraco que ocorre proporcionalmente a uma diminuição do grau da faculdade da memória do sujeito. Convém notar ainda que o obscuro é um grau de consciência muito tênue, porém, sem implicar um completo desaparecimento da própria consciência, uma vez que Kant afirma que a consciência tem um grau que 

representações obscuras no caso do enfraquecimento do grau da faculdade da atenção, mas este ponto será explicado adiante no tópico das representações inconscientes, pelo fato de ele aproximar estes dois conceitos neste contexto).

O segundo aspecto da definição do obscuro aparece no texto da Antropologia, onde Kant escreve: é obscuro se “(...) podemos ser mediatamente conscientes de ter uma representação, mesmo que não sejamos imediatamente conscientes dela" (Antr., Ak135 - itálicos acrescentados). Este segundo ponto pode ser mais bem compreendido ao levar-se em consideração o primeiro, pois à medida que a representação obscura é muito fraca, dada a debilidade de algumas das faculdades do sujeito, então sua percepção só é possível através de outras representações, tais como as claras e as distintas. Kant explica isto através do exemplo das representações obscuras na percepção da energia magnética devido à debilidade em grau dos sentidos:

\begin{abstract}
Assim, nós conhecemos a existência de uma matéria magnética, que perpassa todos os corpos, a partir da percepção da limalha de ferro atraída pelo ímã, ainda que uma percepção imediata dessa matéria nos seja impossível em virtude da constituição de nossos órgãos (...) (CRPu, B273 itálico acrescentado).
\end{abstract}

Neste exemplo, vê-se que, embora a energia magnética seja uma representação obscura, pois é imperceptível aos sentidos humanos, todavia, ela pode ser percebida indiretamente mediante as representações claras, ou seja, as limalhas de ferro.

\title{
b) A obscuridade nas sensações
}

Kant trata também das representações obscuras sensíveis, isto é, daquelas que são ligadas à sensação. Assim, escreve ele: "Que seja imenso o campo das nossas sensações e intuições sensiveis, isto é, das representações obscuras no ser humano (...)" (Antr. Ak135 - itálico acrescentado). Mais adiante, ele esclarece que tais 
representações “(...) só deixa perceber o ser humano em sua parte passiva, como jogo das sensações (...)" (Antr., Ak136).

Kant exemplifica de diversas maneiras a ocorrência das representações obscuras de natureza sensível (sensação), tal como no exemplo do homem no prado (Antr., Ak135), no da percepção da força magnética entre os imãs (CRPu, 273), no das ilusões ópticas (Antr., Ak149-50) e no do músico compondo uma fantasia (CRP, B415 e Antr., Ak136).

Através da menção a tais exemplos, vê-se que Kant admite que as representações obscuras na sensação constituem um amplo campo. No título Das representações que temos sem delas sermos conscientes ele afirma:

\begin{abstract}
Que seja imenso o campo das nossas sensações e intuições sensíveis, isto é, das representações obscuras no ser humano (...), de que não somos conscientes, ainda que possamos concluir indubitavelmente que a temos; que, ao contrário, as representações claras contenham apenas infinitamente poucos pontos acessíveis à consciência; que, por assim dizer, no grande mapa de nosso espírito só haja poucos lugares iluminados, isso pode nos causar espanto com relação a nosso próprio ser (...) (Antr., Ak135).
\end{abstract}

Assim, se fosse desconsiderado todo esse campo das representações sensíveis (obscuras), o que restaria das representações? Se tomarem-se como válidos apenas os dados conscientes (claros ou distintos), restaria ao conhecimento humano, de acordo com Kant, algo muito limitado e vago no âmbito das sensações, visto que estas sempre comportam obscuridade.

No campo da sensação, Kant afirma que o real de um fenômeno constitui a matéria do mesmo, que é a sensação. Esta, por sua vez, não possui uma quantidade extensiva - que vá das partes ao todo - mas apenas intensiva, ou seja, um grau determinado que preenche apenas um momento; isto significa que "a ausência de sensação no mesmo instante representaria este como vazio, logo = 0" (CRPu, B209). No entanto, este grau zero de sensação não é visto em sentido absoluto, posto que Kant afirma que as sensações prosseguem em uma escala infinita de graus cada vez menores: "Entre a realidade no fenômeno e a negação, portanto, há uma 
concatenação contínua de muitas sensações intermediárias possíveis, em que a diferença de umas em relação às outras é sempre menor do que a diferença entre a sensação dada e o zero da negação completa" (CRPu, B210). Ou seja, o 0 (zero) pode ser visto apenas como um limite para o qual tendem, ao infinito, as diferenças de graus cada vez menores de sensações, porém sem nunca atingir tal limite absolutamente. Por sua vez, a esta escala de sensações, corresponde, nos órgãos dos sentidos, “(...) um determinado grau de receptividade das sensações (...)" (CRPu, B214), ao que determinadas sensações ínfimas podem estar fora da capacidade de tal receptividade. Portanto, o grau de sensação=0 tem sentido epistêmico e não ontológico, na medida em que tal grau nulo de sensação é relativo à incapacidade sensorial e cognitiva do sujeito de representar algo, e não à ausência absoluta de algo (sensação) possível de ser representado.

Assim, ainda que não seja possível tornar-se consciente de todo o campo das sensações, isto não significa, contudo, que não há qualquer grau de sensação - se fosse assim, existiriam inúmeros espaços vazios, dada a limitação dos sentidos. Neste aspecto, comenta Loparic, em sua Semântica transcendental (2005, p.167), que "é impossível representar toda a multiplicidade pensável das partes de uma sensação no domínio dos dados sensíveis conscientes". Diante de tal fato, (i) ou limita-se "as partes da sensação ao domínio de representações conscientes", ao que neste caso negar-seia "a validade objetiva do conceito de sensação não efetivamente possível"; (ii) ou teria de se encontrar "meios para estender o conceito de dado intuitivo além da classe de dados dáveis de modo efetivo. Kant escolheu a segunda alternativa e admitiu sensações de fato inacessíveis para nós como elementos que constam do domínio da experiência possível". Tudo isso somente indica a existência de um campo de sensações das quais não se podem ser imediatamente consciente, o que não anula a possibilidade se serem tornadas tal, de forma mediata.

Kant ilustra, na Antropologia, com um exemplo similar ao da $C R P u$, mas enquanto lá era a sensação da energia magnética que era percebida mediatamente, 
Souza, L. E. R.; Brito, A. B. S.

As representações sem consciência em Kant

aqui é a representação sensível (obscura) da visão de um homem no prado que é feita mediante representações claras:

Se estou consciente de estar vendo, distante de mim, um ser humano num prado, mesmo não estando consciente de ver-lhe os olhos, nariz, boca, etc., concluo de fato apenas que essa coisa é um ser humano, pois se quisesse afirmar que não tenho absolutamente a representação dessas partes da cabeça (...), porque não sou consciente de percebê-las, então também não poderia dizer que vejo um ser humano: pois a representação total (da cabeça ou do ser humano) é composta dessas representações parciais (Antr., Ak135).

Historicamente, na recepção da filosofia crítica à época de Kant, a noção de grau de sensação é desenvolvida em pelo menos dois pensadores: Maimon e Fichte. Com efeito, Maimon (1790), retomando esta concepção de Kant, também admite o campo de sensações das quais não se tem consciência e busca na teoria dos diferenciais de Leibniz, uma explicação para essas sensações imperceptíveis. Para Maimon, a consciência é alcançada ao se chegar a um diferencial, a um grau que é suficiente à consciência:

Assim como, por exemplo, num movimento acelerado a velocidade anterior não desaparece, mas vai sempre adicionar-se à seguinte, de onde resulta uma velocidade cada vez maior, assim também não desaparece a primeira representação sensível, que vai antes associar-se sempre às seguintes, até alcançar o grau que é necessário à consciência (...). (MAIMON, 1992 [1790], p.224).

Por sua vez, Fichte (1794) sustenta a variação de grau de sensação visual, relativo à presença ou a ausência de luminosidade. No exemplo repetido várias vezes por ele, o filósofo concebe um espaço contínuo em que os pontos extremos contêm duas sensações opostas, a luz e a treva, e cuja região intermediária é constituída pela sensação da penumbra. Por conseguinte, conclui ele, "luz e treva não são em geral opostas, mas distinguem-se apenas segundo graus. A treva é apenas uma quantidade exígua de luz" (Doutrina da ciência, B145).

\section{c) A obscuridade no domínio teórico, prático e estético}


Inúmeros são as referências de Kant quanto à presença de uma obscuridade ou não consciência no campo do conhecimento, da ética e da estética. Embora Kant tenha afirmado na Antropologia que apenas uma consciência distinta "é a única que faz de uma soma de representações um conhecimento (...)" (Ak138), isto não invalida dizer que ele reconhece a existência de representações obscuras envolvidas nos domínios cognitivos, volitivos e estéticos.

Em primeiro lugar, no domínio teórico, Kant afirma que "a maior parte do entendimento ocorre na obscuridade", ou melhor, "todos os atos do entendimento e da razão podem ocorrer na obscuridade" (Refl., apud, 2009); que “(...) toda ligação quer sejamos dela conscientes ou não (...) - é um ato do entendimento" (CRPu, B130). Além disso, ele apresenta o fato de muitos processos que culminam no próprio conhecimento objetivo é realizado de forma obscura, tal como é o caso do próprio esquema, visto na seguinte passagem:

Este esquematismo de nosso entendimento, em relação aos fenômenos e sua mera forma, é uma arte oculta nas profundezas da alma humana, cujas verdadeiras operações dificilmente conseguiremos decifrar na natureza, de modo a tê-las descobertas diante de nossos olhos (...) (CRPu, B180-1).

O mesmo se diz dos conceitos produzidos pelo entendimento: "Todo conhecimento exige um conceito, podendo este ser tão imperfeito ou obscuro como seja (...)” (CRPu, A106). E ainda: “(...) o conceito deste (o objeto), porém, tal como é dado, pode conter muitas representações obscuras que não percebemos ao analisá-lo, muito embora o utilizemos sempre na aplicação (...)" (CRPu, B 756). Convém notar que, mesmo que prevaleça uma obscuridade, há sempre algum grau de consciência presente em tais processos cognitivos, tal como observa Kant ainda com relação aos conceitos:

(...) Esta consciência pode muitas vezes ser fraca, de tal modo que só a conectamos à produção da representação no resultado, não no ato mesmo, imediatamente dessa distinção, contudo, uma consciência, mesmo que the falte clareza acentuada, tem de estar sempre presente, e sem ela são 
impossíveis os conceitos e, com eles, o conhecimento do objeto (CRPu, A104).

Em segundo lugar, no domínio prático, Kant destaca uma obscuridade, em pelo menos dois sentidos distintos. De um lado, enquanto uma falta daquela consciência necessária ao conhecimento objetivo, como é o caso da liberdade: “(...) o fundamento, para nós insondável, desta propriedade [a liberdade] é um mistério, porque não nos é dado em ordem ao conhecimento" (Religião, p. 144 - itálico acrescentado). De outro, enquanto uma propensão de não prestar atenção ao julgamento da consciência, afinal, o agir moralmente implica uma consciência moral, que é inerente ao sujeito:

Assim, quando se diz que um certo ser humano não tem consciência, o que se quer dizer com isso é que ele não presta atenção à sentença da consciência, pois se ele realmente não tivesse consciência, não poderia sequer conceber o dever de ter uma, visto que nem imputaria alguma coisa a si mesmo em conformidade com o dever, nem censuraria a si mesmo com alguma coisa como contrária ao dever (DV, XIII, p. 243).

Por fim, em terceiro lugar, no domínio estético, Kant revela que há uma obscuridade relacionada ao uso da faculdade da imaginação na produção da experiência estética. Para ele, a imaginação está “(...) menos sob pressão das regras que de outras faculdades (...)" (Antr., Ak225), de modo que o filósofo situa nesta faculdade grande parte das representações obscuras ou sem consciência.

$\mathrm{Na}$ CFJ, Kant confere à faculdade da imaginação uma dada preeminência sobre as demais, ainda que ela necessite estar em concordância com o entendimento e a razão. Segundo ele, a imaginação é apresentada como um poder capaz de produzir uma 'outra natureza', ou seja, ela é capaz de ultrapassar os próprios dados que nos são fornecidos pela sensibilidade:

A faculdade da imaginação (enquanto faculdade de conhecimento produtiva) é mesmo muito poderosa na criação como que de uma outra natureza a partir da matéria que a natureza efetiva lhe dá (...). Também a remodelamos de bom grado, na verdade sempre ainda segundo leis analógicas, mas contudo também segundo princípios que se situam mais 
acima da razão (...). Neste caso sentimos nossa liberdade da lei da associação (...) de modo que segundo ela na verdade tomamos emprestado da natureza a matéria, a qual porém pode ser reelaborada por nós para algo diverso, a saber, para aquilo que ultrapassa a natureza (CFJ, B193).

Pode-se citar diversos exemplos das produções da imaginação que implicam em uma obscuridade ou não consciência por parte do sujeito, como é o caso da elaboração do ideal da beleza, apresentado na CFJ, onde a imaginação 'sabe de um modo totalmente incompreensível a nós', evocar incontáveis conceitos e imagens passados, sendo ainda capaz de compará-los entre si e deles extrair um intermediário9 .

Além deste, há o exemplo peculiar, já brevemente aludido por Kant na CRPu, sobre o músico na composição de uma fantasia, que é retomado detalhadamente na Antropologia:

(...) Quando um músico toca com dez dedos e ambos os pés uma fantasia ao órgão, e ainda fala com alguém que se encontra ao seu lado, um grande número de representações é em poucos instantes despertado na alma, representações que exigiriam, para a escolha de cada uma delas, um juízo particular sobre sua adequação, porque um só movimento de dedo destoando da harmonia seria imediatamente percebido como dissonância; e no entanto o todo produz tal resultado, que o músico, improvisando livremente, desejaria com frequência conservar, em notação musical, algumas das peças executadas por ele, peças que, por mais que se aplique, talvez não tenha esperança de realizar de novo tão bem (Antr., Ak136; CRPu, B415 n.).

Neste último exemplo, é importante observar que Kant usa o conceito de obscuro em referência a dois objetos distintos, a saber: a sensação e os processos intelectuais. Pois, de um lado, Kant apresenta este exemplo como relativo às sensações obscuras auditivas, no sentido de que ele entende a própria música como

\footnotetext{
${ }^{9}$ A descrição de Kant para esse processo não consciente de elaboração do ideal da beleza por parte da imaginação dá-se da seguinte maneira: "Deve-se observar que a faculdade da imaginação sabe, de um modo totalmente incompreensivel a nós, não somente revocar os sinais de conceitos mesmo de longo tempo atrás, mas também reproduzir a imagem e a figura do objeto a partir de um número indizível de objetos de diversas espécies ou também de uma e mesma espécie; e igualmente, se o ânimo visa comparações, ela, de acordo com toda a verossimilhança, se bem que não suficientemente para a consciência, sabe efetivamente como que deixar cair uma imagem sobre a outra e, pela congruência das diversas imagens da mesma espécie, extrair uma intermediária, que serve a todas como medida comum. (...)" (CFJ, B57 - itálico acrescentado).
} 
um "jogo regular de sensações auditivas" (Antr., Ak155); de outro, ele destaca a faculdade da imaginação na produção artística, como a fonte da originalidade do gênio. Esse último ponto é particularmente notável pela referência de Kant à fantasia $^{10}$, uma forma musical tipicamente alemã que estava em seu auge na sua época e que consistia em uma livre improvisação por parte do músico. A questão que Kant coloca é de como o músico consegue, na liberdade da improvisação, produzir uma composição tão harmônica, mesmo sem o auxílio de qualquer regra musical. Na explicação desta questão, Kant recorre ao conceito de gênio, como o talento "por meio do qual a natureza dá regra à arte" (Antr., Ak226), ainda que isso se passe de forma não consciente: “(...) quem tem esse talento não pode explicar para si mesmo os arroubos dele, nem tampouco tornar compreensível para si mesmo como chega a uma arte que não pôde aprender" (Antr., Ak225) ${ }^{11}$.

Na livre fantasia (como gênero musical), apresentam-se ao músico uma gama de representações dos quais ele não tem consciência: é o próprio jogo da imaginação como fantasia, ou, em outras palavras, "a imaginação, quando produz involuntariamente ficções, se chama fantasia" (Antr., Ak167). Mas, mesmo neste jogo, o músico encontra uma regra para ordenar tais representações na produção de sua composição - a imaginação no gênio concorda com o entendimento, ainda que não esteja a ele subordinada -, ou melhor, ele pode não ser consciente de seus arroubos, de como produz sua arte, porém, como o músico se guia necessariamente por alguma regra, ainda aí se encontra uma determinada consciência ou grau de consciência, do contrário recairia num estado de loucura, ou em um sonho:

\footnotetext{
${ }^{10}$ A fantasia é um gênero musical tipicamente alemão presente no séc. XVIII e consistia em uma improvisação por parte do músico, num estado 'sonhador': “O desenvolvimento da fantasia com relação a uma liberdade cada vez maior comparada às restrições formais, portanto, confirma, como Schleuning aponta, que "o desempenho de improviso era o meio essencial para a livre fantasia (...). A tarefa do músico era "instigar e acalmar muitas emoções na conclusão" e "efetuar a repentina mudança inesperada de uma emoção para a outra" de forma que "a emoção do púbico domine (...)" (KNELLER, p. 175).

${ }^{11} \mathrm{Em}$ sentido semelhante, Kant escreve na CFJ (§46, B182): o gênio "é um talento para produzir aquilo para o qual não se pode fornecer nenhuma regra determinada", de modo que "ele próprio não pode descrever ou indicar cientificamente como ele realiza sua produção".
} 
A diferença entre o músico da fantasia e o sonhador, para Kant, é o fato de que o organicista desenvolveu grandes habilidades técnicas a tal nível que poderiam ser acessadas sinestesicamente, ou seja, quase inconscientemente. Há, então, um sentido no qual o improvisador não é um artista "consciente". Em vez disso, é um artista que tem uma escolha conscientemente em um estado sonhador a fim de deixar sua imaginação "brincar" com suas decisões sobre quais ideias musicais expressará. O resultado é um objeto natural, não um “composto" (KNELLER, 2010, p.178).

\section{As representações inconscientes}

Gödde (1999) situa em Leibniz o primeiro momento da elaboração, por assim dizer, do conceito de inconsciente que mais tarde será desenvolvido e ampliado pelos românticos e, em seguida, por Schopenhauer e Nietzsche, alcançando um estatuto conceitual mais sistematizado em Freud. É Leibniz que representa a primeira investida, a primeira resposta à concepção do eu consciente privilegiada por toda uma tradição que remonta até Descartes. Em Leibniz, o inconsciente é caracterizado, segundo Gödde, como algo que é confusamente percebido, de maneira tão vaga e indistinta quanto os 'murmúrios do mar', tal como se pode ver neste trecho do Discurso da Metafísica (§33):

\footnotetext{
Vê-se também que as percepções dos nossos sentidos, mesmo quando sejam claras, devem conter necessariamente algum sentimento confuso, pois, simpatizando todos os corpos do universo, o nosso recebe a impressão de todos os outros e, embora os nossos sentidos se refiram a tudo, é impossível nossa alma a tudo atender em particular. Por isso são os nossos sentimentos confusos o resultado duma variedade completamente infinita de percepções. E é quase como o murmúrio confuso ouvido por quem se aproxima da beira do mar e proveniente da reunião das repercussões de vagas inumeráveis. Ora, se de diversas percepções (...) nenhuma há que exceda as outras, e provocam mais ou menos impressões igualmente fortes ou igualmente capazes de determinar a atenção da alma, esta só pode apercebê-las confusamente (1999, p. 148).
}

Kant tem assim toda uma tradição conceitual, uma matriz de referências, por assim dizer, acerca do conceito de obscuro, a qual tem de considerar para a própria elaboração de seu conceito. Não somente Leibniz, mas Wolf e Baumgarten discutem 
acerca das representações claras e obscuras ${ }^{12}$, embora possamos situar em Leibniz, com maior destaque, por assim dizer, uma concepção mais elaborada sobre o tema. Pode-se mesmo colocar em Leibniz a existência de uma teorização acerca do inconsciente, este concebido em um duplo sentido, a saber, o de ideias inconscientes como obscuras referidas a percepções inapercebidas, e o de ideias inconscientes como 'confusas' - similarmente, vê-se que Kant trabalha com uma compreensão em sentidos diversos sobre o inconsciente. Conforme sustenta HEIDEMANN (2012):

\begin{abstract}
Assim, Leibniz distingue basicamente entre duas espécies de ideias inconscientes. Primeiramente, ideias inconscientes são ideias obscuras. Elas são uma espécie de percepção, como ele diz na Monadologia (1714), '(...) que não de apercebe', embora sejam diferentes da percepção dos sentidos e da consciência. Posteriormente, ideias inconscientes são ideias confusas, ie., ideias claras que permitem a diferenciação, todavia, não de um modo distinto que exija o conhecimento da natureza de algo (...) (2012, p. 42-43).
\end{abstract}

Já em Kant, o termo 'inconsciente' (unbewusst), de acordo com Brandt, fora admitido como uma expressão não usada por Kant, como aponta Valério Rohden (2009, p. 6): “Mais controversa é a afirmação de Brandt de que Kant não usa o termo unbewusst (inconsciente), embora Rudolf Eisler o tenha incluído em seu Kant-Lexikon (1930)". O termo aparece, contudo, em vários momentos nas obras de Kant, embora com menos frequência do que o 'não consciente' (nicht bewusst) e 'obscuro' (Dunkel). De modo geral, nunca é usado como substantivo (Unbewusst), mas sempre como uma forma adjetiva (unbewusst - $u$ minúsculo), caracterizando o estado passageiro em que a consciência não se faz presente.

Este sentido é evidenciado no trecho da Antropologia (Ak166) acerca do sono, o qual seria formado por instantes em que "o homem se vê no mundo igual a um recém-nascido e durante o qual transcorre, inconscientemente (unbewusst) e sem pesar, um terço de nosso tempo de vida." Na mesma perspectiva, há este trecho da

12 Kant não é indiferente a tais discussões, tanto que se pronuncia acerca da concepção de Leibniz e Wolf acerca do conceito de ideia confusa no que se refere às representações claras: para ele, uma representação clara ou é distinta ou indistinta e não confusa (uma representação que não é distinta, é indistinta - Log., Ak34). Para um maior aprofundamento da questão ver Kant e la rappresentazioni "chiare e confuse" (PROCURANTI, 2008). 
Lógica Jäsche (Ak11) em referência às faculdades em geral e a da linguagem em particular:

O exercício de nossas faculdades também se faz segundo certas regras, que seguimos inicialmente, inconscientes [unbewussten] delas, até que, mediante tentativas e um demorado uso de nossas faculdades, chegamos ao seu conhecimento (...). Do mesmo modo, a gramática geral, por exemplo, é a forma de uma língua em geral. Mas falamos mesmo não conhecendo a gramática, e quem não a conhece e, no entanto, fala, possui na verdade uma gramática e fala segundo regras de que não tem consciência (itálicos acrescentados).

Neste exemplo, as faculdades do sujeito seguem sempre regras, pois, para Kant, tudo na natureza "(...) ocorre segundo regras, embora nem sempre conheçamos essas regras de imediato. (...)" (Lóg. AK11). Do mesmo modo se passa com a gramática, pois falamos muitas vezes sem conhecer as regras gramaticais, falamos, como diz Kant, inconscientes das regras que seguimos, bem como nos utilizamos de nossas faculdades sem conhecer as regras pelas quais elas se guiam. Nada impede, entretanto, que através de um uso demorado, isto é, de um esforço e reflexão por parte do sujeito, não se chegue à consciência de tais regras.

Assim, a inconsciência implica em um desaparecimento de fato da consciência, mas temporária, um caso em que ela, embora exista no sujeito, é afetada por uma limitação cognitiva ou uma desatenção da sua parte. É neste sentido que deve ser também compreendida a afirmação de Kant de que 'há vários graus de consciência até seu desaparecimento' (CRPu, B415). Para Kant, trata-se de um ato de voltar a atenção para aquilo que se é, a princípio, inconsciente: "O esforço para chegar a ser consciente das próprias representações é ou atenção (attentio) ou abstração [abstractio] de uma representação de que sou consciente" (Antr., Ak131).

É evidente que esse esforço para se chegar a ser consciente possui um limite, afinal não é possível chegar ao conhecimento de todas as regras na natureza. Para Kant, conforme ROHDEN (2009, p. 7), “(...) se o homem pudesse ser consciente de 
todas as representações que ocupam a alma, seria uma espécie de divindade", e neste sentido, o inconsciente representa um limite da capacidade de conhecer.

O termo 'inconsciente' também aparece sob outra forma, não somente como o adjetivo unbewusst, mas como os substantivos Gewissenlos ou Gewissenlosigkeit ${ }^{13}$, os quais significam também 'inconsciente', mas ligado ao aspecto moral. Assim, observa Kant, a "inconsciência (Gewissenlosigkeit) não é falta de consciência, mas a propensão de não prestar atenção a seu julgamento. (...)" (DV, p.243). Noutra passagem, ele afirma: “(...) atribuir uma lata consciência a alguém resulta em classificálo como inconsciente (Gewissenlos)" (DV, §13, p. 282). Assim, a definição do estado de inconsciência como um déficit ou falta de atenção é mantida por Kant e, em particular, no campo da moral, mais do que em qualquer outro. Na ética é praticamente inaceitável excluir a consciência das ações, ou melhor, o homem age guiado por uma consciência moral, ela é como que o juiz interno que julga como se deve agir:

Todo ser humano tem uma consciência e se vê observado, ameaçado e, em geral, conservado no assombro (respeito associado ao medo) por um juiz íntimo, e esta autoridade, vigilante da lei dentro dele, não é algo que ele próprio (voluntariamente produz), mas algo incorporado em seu ser. Acompanha-o como sua sombra quando ele planeja escapar. Ele pode, realmente, atordoar-se ou reduzir-se ao sono por força de prazeres e distrações, mas não consegue voltar a si ou despertar de tempos a tempos; e quando o faz, ouve imediatamente aquela voz terrível. Ele pode, no máximo, na extrema abjeção, conseguir não dar mais atenção a ela, mas não pode ainda deixar de ouvi-la ( $D V, \S 13$, p. 280).

Para finalizar este tópico, convém salientar que, em certo sentido, Kant aproxima, às vezes, o significado do inconsciente (unbewusst) ao do próprio obscuro (Dunkel). De fato, ele concebe o inconsciente como uma representação associada a um déficit de atenção, enquanto o obscuro como uma representação fraca devido a uma limitação nas faculdades em geral (memória, atenção, linguagem, sentidos, conceitos). A seguinte passagem da Lógica (Ak33) ilustra este outro significado do obscuro

\footnotetext{
${ }^{13}$ Gewissen no alemão denota uma consciência especificamente ligada ao aspecto moral; o acréscimo da terminação los (em Gewissenlos) implica em uma negação que equivaleria a 'sem escrúpulos'; no caso da terminação losigkei (em Gewissenlosigkeit) significa "falta de consciência, falta de escrúpulos".
} 
próximo ao do inconsciente: “(...) Se estou consciente de minha representação, ela é clara (klare); se não estou, é obscura (dunkele) (itálico acrescentado)". Com feito, o obscuro aqui significa uma representação não consciente de modo subjetivo, o que quer dizer que o sujeito não tem consciência momentânea de uma representação por falta de atenção, mas que pode vir a tê-la em outro momento, desde que dirija sua atenção a mesma, de modo que, neste caso, o obscuro é entendido no sentido de uma representação inconsciente (unbewusst). Estas observações sugerem, em uma visão mais radical, que as representações inconscientes podem ser compreendidas como uma espécie das próprias representações obscuras, na medida em que aquelas são definidas em função da variação diminuta dos graus de uma faculdade específica do sujeito, a saber, a da atenção. Isto dá a entender que Kant nomeia de modo especial as representações obscuras que envolvem uma debilidade da faculdade da atenção, chamando-as, neste caso, de inconscientes. De modo amplo, esta interpretação insinua que a variação geral dos graus (da faculdade) de atenção produzem as representações tanto inconscientes como conscientes, na medida em que envolvam graus de atenção quer reduzido quer ampliado, respectivamente.

\section{As representações sem consciência em Kant e Locke}

Neste tópico será destacado um debate que Kant estabelece com Locke acerca das representações sem consciência em que ambos sustentam teses distintas. Em linhas gerais, de um lado, Locke (1690) defende que não há representações sem consciência, cuja hipótese envolve contradição, tal como evidenciado no exemplo do eu e do sonho; de outro, Kant argumenta que há representações sem consciência, refutando a posição daquele mediante a sua concepção do obscuro e do inconsciente contextualizada nos mesmos exemplos acima.

Para Locke, as representações sem consciência são inadmissíveis, pois, “(...) é muito difícil imaginar que alguma coisa possa pensar e não estar consciente disso (...). Ser feliz ou miserável sem ter consciência disso parece-me totalmente inconsistente e impossível. (...)" (LOCKE, 1991 [1690], p. 30). No caso do eu, segundo ele, a existência 
de representações sem consciência colocava em questão a própria 'identidade pessoal do sujeito', pois, tendo ele representações das quais não pode ser consciente, não estaria aí colocado dois sujeitos, um a quem pertencem as representações e outro para o qual elas são totalmente estranhas? No caso do sonho, ele não admite que a alma pense durante esse tempo: "Quando o corpo dorme é impossível que a alma tenha pensamento (...). Se for excluída totalmente a consciência de nossas ações ou sensações, (...), juntamente com os problemas que acompanham, será difícil caracterizar a identidade pessoal" (LOCKE, 1991, p. 30-1).

Retomando o argumento de Locke, pode-se considerá-lo como resumido em três principais pontos: (1) pensar e não ser consciente parece ser algo no mínimo contraditório, por isso são impossíveis representações sem consciência; (2) por isso, é preciso se admitir que no sonho a alma não pensa; (3) um outro argumento que reforça a inexistência de representações sem consciência, é o fato de que, se elas realmente fossem possíveis, isso colocaria em questão a identidade do sujeito, ele não teria como ser um único 'eu'.

Na Antropologia (§5), pode-se dizer que Kant retoma e refuta o ponto (1) acima do argumento de Locke, através do seu conceito de representações obscuras, na medida em que estas possuem graus e podem ser mediatas, ou seja, não há uma total ausência de consciência, apenas uma ausência de consciência imediata ou então em grau muito reduzido:

Ter representações, e contudo não ser conscientes delas, nisso parece haver uma contradição, pois, como podemos saber que as temos se delas não somos conscientes? Essa objeção já a fez Locke, que também por isso rejeitou a existência de semelhante espécie de representações. - No entanto, podemos ser mediatamente conscientes de ter uma representação, mesmo que não sejamos imediatamente conscientes dela (Antr., Ak135).

Kant admite, assim, a existência de representações não conscientes sem que isso envolva qualquer contradição: é possível pensar sem se ser consciente disso, porque o pensamento envolve necessariamente alguma forma de obscuridade ou de 
inconsciência, isto é, há sempre um determinado grau de consciência (obscuridade) ou falta de atenção (inconsciência) envolvido em toda atividade consciente.

No exemplo do sono, Kant afirma uma tese contrária a de Locke, ao defender que tanto no sono como na vigília há graus de obscuridade e clareza, sendo esta uma ideia presente desde seus escritos pré-críticos:

(...) Certos filósofos acreditam poder apelar sem o mínimo temor de objeção ao estado do sono profundo, quando pretendem demonstrar a efetividade de representações obscuras, uma vez que nada se pode dizer com certeza acerca disso, a não ser que não lembramos no estado de vigília de nenhuma daquelas representações que podemos ter tido no sono profundo, do que segue apenas que elas não foram representadas claramente no despertar, mas não que também então, quando dormíamos, elas eram obscuras. Eu conjecturo antes que elas possam ser mais claras e extensas do que as mais claras no estado de vigília, porque isso é de esperar de um ser tão ativo quanto à alma (...) (Sonhos de um visionário, 1766, II 338).

Na Antropologia (Ak166), Kant define o sono como um “(...) estado de incapacidade, em um ser humano saudável, de poder se tornar consciente das representações pelos sentidos externos" e, em seguida, afirma esse estado passageiro como sendo de uma inconsciência; seria um momento da vida humana em que "o homem se vê no mundo igual a um recém-nascido e durante o qual transcorre, inconscientemente (unbewusst) e sem pesar, um terço de nosso tempo de vida". Essa inconsciência, entretanto, não anularia a atividade intelectual: "Talvez no mais profundo sono se exerça a máxima perfeição da alma no pensamento racional" (Refl., apud, 2009). Para Kant, não ser consciente de algo não implica que aí não haja atividade intelectual e, neste sentido, comenta Valério Rohden (2009, p. 7), que "Kant tem uma concepção positiva do inconsciente, que envolve uma variedade de operações (...).".

No exemplo do eu, em que Locke levanta a hipótese de que as representações sem consciência culminem em uma cisão do eu, Kant praticamente elimina essa possibilidade através do eu lógico, dessa unidade formal da apercepção transcendental. Segundo Kant, a apercepção transcendental - diferentemente da 
Souza, L. E. R.; Brito, A. B. S. As representações sem consciência em Kant empírica - é a possibilidade estrutural do pensamento e de toda representação possível - seja ela consciente ou não consciente:

Não se deve perder de vista, contudo, que a representação eu é, em relação a todas as outras (cuja unidade coletiva ela torna possível), a consciência transcendental. Pouco importa aqui se essa representação é clara (consciência empírica) ou obscura, ou mesmo se é efetiva; mas a possibilidade da forma lógica de todo conhecimento se baseia necessariamente na relação a essa apercepção como uma faculdade (CRPu, A177).

Assim, mesmo representações não conscientes precisam estar ligadas a apercepção pura, a um eu ${ }^{14}$ idêntico que é sempre uno. Essa ligação necessária garante sempre a possibilidade de tornar algo não consciente, em consciente, segundo nota La Rocca (apud, 2009.):

(...) A apercepção transcendental é uma possibilidade indispensável: o campo do entendimento é o da possibilidade de algo tornar-se consciente. Se admitimos a consciência transcendental como uma possibilidade estrutural, então a ideia de um entendimento obscuro não é nem contraditória nem prejudicial.

A ideia de uma apercepção pura ser essa unidade que garante sempre uma consciência formal exclui, assim, a possibilidade de um eu sem consciência alguma e, portanto, a cisão em dois 'eus' - um consciente e outro inconsciente ${ }^{15}$.

\footnotetext{
${ }^{14}$ Também o conceito desse eu da apercepção pura é definido de maneiras diversas em Kant, ora como um conceito (representação clara), ora como um sentimento ou uma sensação (representação obscura). Com efeito, na CRPu (B399), Kant confere ao eu um estatuto conceitual, ao escrever: "Chegamos agora a um conceito que não foi mencionado acima, na lista dos conceitos transcendentais (...). Trata-se do conceito ou, se preferir, do juízo eu penso". Contrariamente, nos Prolegômenos tal representação "não é mais que o sentimento de uma existência sem o mínimo conceito, e simples representação sem a qual todo pensamento está em relação" (A136 - itálico acrescentado). Já nas Reflexões (3921) o eu é sem conceito, sendo apresentado como sensação: "Por isso, também não é estranho que nós não reconheçamos o sujeito perante todos os predicados, como simplesmente o eu que, sem embargo, não é conceito, mas uma intuição (sensação)" (apud,1998-1999); de modo semelhante, nas Reflexões, ele também é dito uma representação obscura: "O eu é uma representação obscura. Ela é uma intuição, a qual é invariável” (XVII, 465) (Os grifos acrescentado nestas passagens são dos autores).

${ }^{15}$ Kant compreende o inconsciente numa acepção adjetiva, ou seja, como qualificando o estado do sujeito e não como sendo um gênero ou sistema independente - tal como aparecerá mais tarde na terminologia psicanalítica. De fato, não há um inconsciente (Unbewusst - u maiúsculo), porque a consciência ainda é o pressuposto para o pensamento, uma consciência formal a qual estão atreladas
} 


\section{Considerações finais}

Ao longo deste trabalho revelou-se o sentido geral das representações sem consciência (ohne Bewusst) em Kant, bem como a sua terminologia empregada: não consciente (nicht bewusst), obscuro (Dunkel) e inconsciente (unbewusst, Gewissenlos e Gewissenlosigkeit).

Em seguida, buscou-se justificar as três principais teses defendidas neste trabalho. Quanto à primeira tese, indicou-se que Kant emprega em sentido muito próximo, praticamente equivalente, as expressões 'representações sem consciência' e 'representações não conscientes', enquanto o mesmo gênero, o qual é oposto às representações com consciência ou conscientes. Quanto à segunda tese, mostrou-se que este gênero das representações sem consciência ou não conscientes contém, de um lado, como suas espécies as representações obscuras e as inconscientes, e, de outro, como seus domínios de aplicação os campos teórico, prático e estético. Quanto à terceira tese, justificou-se que Kant compreende em geral as representações obscuras no sentido de um grau de consciência, ao passo que as representações inconscientes no sentido de um déficit de atenção, bem como se indicou que, em certo sentido, estas últimas podem ser vistas como um caso daquelas à medida que a debilidade na atenção decorre de uma redução dos graus de consciência. Por fim, quanto à quarta tese, evidenciou-se que, de acordo com Kant, podem-se denominar as representações sem consciência como percepções obscuras ou indistintas, ao passo que as representações com consciência como percepções claras ou distintas.

Este estudo concluiu que, para Kant, tanto as representações com consciência como as representações sem consciência têm em comum o mesmo domínio: teórico, prático e estético. Além disso, Kant indica com segurança que todas as representações com consciência são acompanhadas, ao mesmo tempo, pelas representações sem

todas as outras. Assim, esta cisão entre dois 'eus' (o eu consciente e o eu inconsciente) não acontece em Kant, mas somente com a psicanálise fundada por Freud, onde o inconsciente aparece como um sistema independente da consciência. 
consciência em todos estes três domínios da razão - em outras palavras, que os processos conscientes da mente são precedidos, auxiliados ou acompanhados por processos não conscientes (obscuros ou inconscientes).

Por último, convém notar que, apesar de a classificação dada por Kant acerca das representações com consciência ser na aparência quantitativamente mais numerosa que as representações sem consciência (ver Apêndice A), não se deve concluir que estas últimas sejam, de fato, quantitativa e qualitativamente menos abrangentes ou relevantes apenas por serem pouco conhecidas ou mesmo totalmente desconhecidas ao sujeito. Afinal, Kant admite que em todos os processos mentais as representações não conscientes ocupam uma região da mente muito mais ampla que a das representações conscientes, semelhante à metáfora do oceano e da ilha, no sentido de que o sujeito consciente é a ilha e o sujeito não consciente é o oceano. 0 trecho abaixo confirma esta conclusão final:

Que seja imenso o campo das (...) representações obscuras no ser humano (e também nos animais), de que não somos conscientes (...); que, ao contrário, as representações claras contenham infinitamente poucos pontos acessíveis à consciência; que, por assim dizer, no grande mapa do nosso espírito só haja poucos lugares iluminados, isso nos pode causar espanto com relação a nosso próprio ser; pois bastaria apenas que um poder superior exclamasse "faça-se luz!", que, mesmo sem o acréscimo de quase nada (por exemplo, se tomamos um literato com tudo o que tem em sua memória), meio mundo, por assim dizer, se abriria diante de nós (Antr., Ak135). 


\section{Referências}

ALLISON, Henry. Idealism: an interpretation and defense (revised and enlarged edition). USA: Yale Univ. Press, 2004.

. El idealismo transcendental de Kant: una interpretación y defensa.

Barcelona: Ed. Anthropos, 1992.

ALMEIDA, Guido Antônio. Kant e a refutação do idealismo. Analytica, Rio de Janeiro, Vol. 17, N. 2, pp. 13-50, 2013.

DELEUZE, Gilles. A dobra: Leibniz e o barroco. São Paulo: Ed. Papirus, 1991.

DESCARTES, René. Princípios da filosofia. Lisboa: Guimarães Ed., 1989.

FICHTE. J. Gottlieb. A doutrina-da-ciência (1794). São Paulo: Ed. Nova Cultural,1988. (Col. Os Pensadores).

GIACOIA, Oswaldo. Nietzsche X Kant. Rio de janeiro: Casa da palavra; São Paulo: Casa do saber, 2012.

GIL, Fernando (org.). Recepção da Crítica da razão pura: Antologia de escritos sobre Kant (1786-1844). Lisboa: Fundação Calouste Gulbenkian, 1992.

GÖDDE, Günter. Traditionsliniendes "Unbewussten": Schopenhauer, Nietzsche, Freud. Alemanha: Diskord (1999).

HEIDEMANN, Dietmar H. 'The 'I Think' must be able to accompany all my representations". Kant's Philosophy of the Unconscious. Berlim/Boston: Walter de Gruyter, 2012.

KANT, Immanuel. Antropologia de um ponto de vista pragmático. São Paulo: Iluminuras, 2006.

A religião nos limites da simples razão. São Paulo: Ed. Escala, [s.d.] A metafísica dos costumes. São Paulo: Edipro, 2003.

Crítica da razão pura. São Paulo: Ed. Vozes, 2012.

Crítica da faculdade do juízo. Rio de Janeiro: Ed. Forense Universitária, 2010. 
Escritos pré-críticos. São Paulo: Ed. UNESP, 2005.

. Manual dos cursos de Lógica geral. São Paulo: Ed. UNICAMP, 2006. . Prolegômenos a toda metafísica futura. Lisboa: Ed. 70, 1988.

KNELLER, Jane. Kant e o poder da imaginação. São Paulo: Ed. Madras, 2010.

LEIBNIZ, Gottfried. Novos ensaios sobre o entendimento humano. São Paulo: Abril Cultural, 1984. (Col. Os pensadores).

Discurso de metafísica. São Paulo: Abril Cultural, 1983. (Col. Os

pensadores).

LOCKE, John. Ensaio acerca do entendimento humano. São Paulo: Nova Cultural, 1988.

LOPARIC, Zeljko. A semântica transcendental. 3. ed. São Paulo: Ed. UNICAMP, 2005. (Coleção CLE, V. 41).

MARTINS, A. Cléia. (1998-1999). Autoconsciência pura, existência e identidade em Kant. Disponível em: www2.marilia.unesp.br. Acesso em:22/05/2012.

PROCURANTI, Lucia. Kant e la rappresentazioni "chiare e confuse". Kant e-Prints. Campinas, Série 2, v. 3, n. 2, p. 245-251, jul.-dez, 2008. Disponível em: $\mathrm{ftp}: / / f t p . c l e . u n i c a m p . b r / . . . / k a n t . . . / P r o c u r a n t i-2-3-2-2$. Acesso em: 01/03/2015.

ROHDEN, Valerio. (2009). Representações não-conscientes em Kant. Disponível em: www.psicaliseefilosofia.com.br. Acesso em: 29/10/2012. 


\section{APÊNDICE A - Classificação da Representação em Geral}

Kant realiza uma classificação geral das representações da mente, partindo do gênero maior das representações em geral e, em seguida, dividindo-o, explicitamente, no gênero das representações com consciência e, implicitamente, no gênero das representações sem consciência (CRPu, B376-7). O quadro abaixo mostra todas as espécies de representações com e sem consciência, admitidas por ele, explícita ou implicitamente:

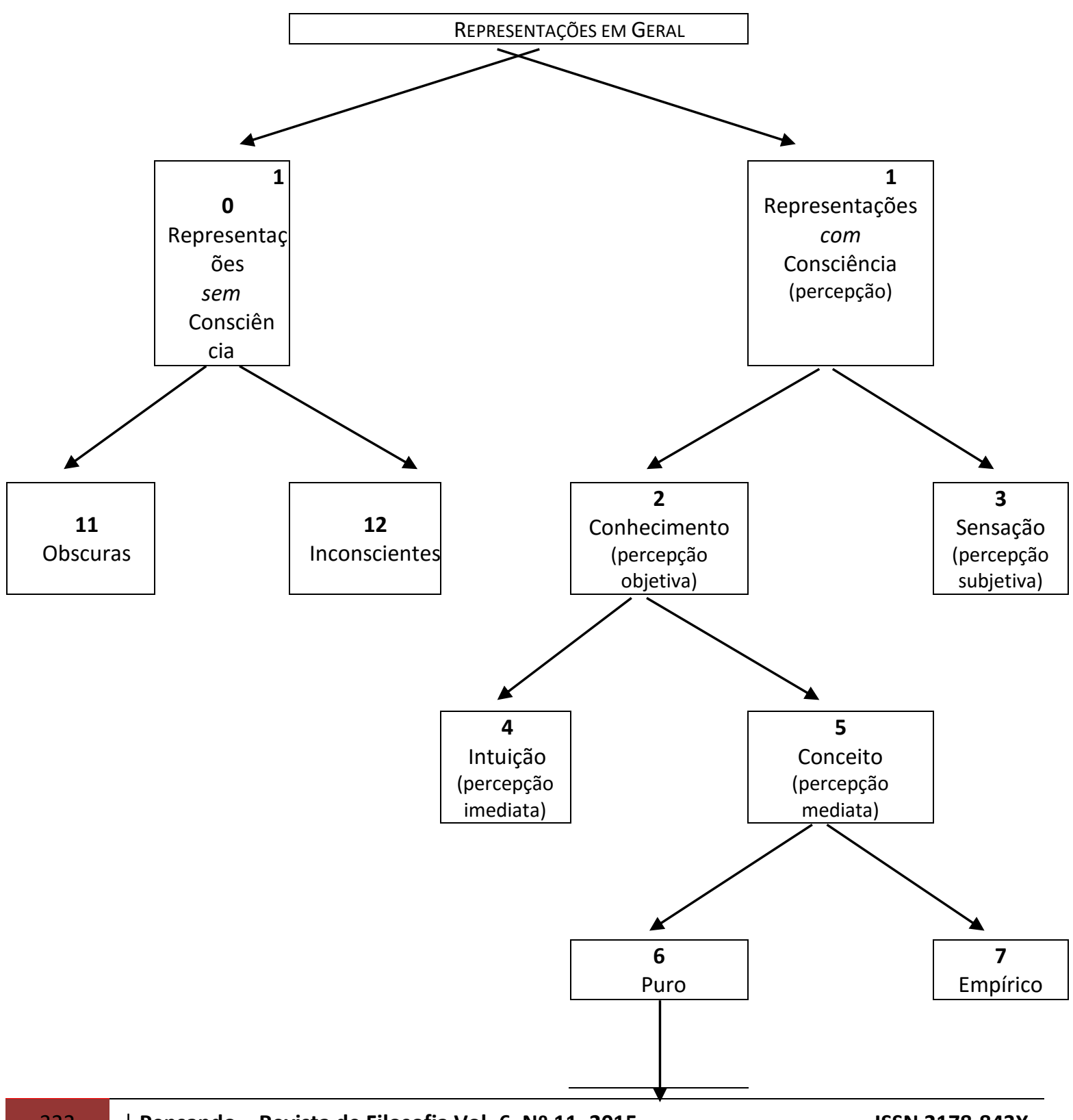




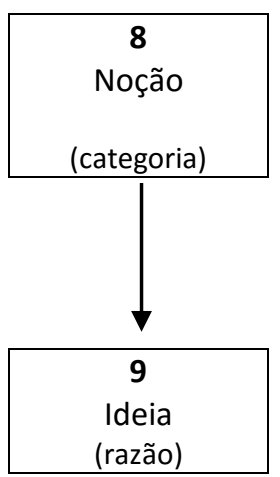

Quadro 1

Convém lembrar que todas as espécies de representações em geral (com consciência e sem consciência) aplicam-se ao aos três principais domínios da razão (teórico, prático e estético).

Deve-se observar que Kant denomina as representações com consciência e suas subdivisões como espécies de percepções. Com efeito, ele chama: (1) a representação com consciência de percepção; (2) o conhecimento de percepção objetiva; (3) a sensação de percepção subjetiva; (4) a intuição de percepção imediata; (5) o conceito de percepção mediata. Embora ele não indique explicitamente, poderse-ia ainda dizer que: (6) o conceito puro é uma percepção mediata pura; (7) o conceito empírico é uma percepção mediata empírica; (8) a noção é uma percepção mediata pura intelectual; (9) a ideia é uma percepção mediata pura racional. Por questão de economia, Kant usa expressões simples ao invés de complexas para designar todas estas espécies de percepções.

Após tais observações, pode-se colocar a seguinte questão quanto às representações sem consciência: elas são também espécies de percepções ou são representações distintas das percepções (por exemplo, espécies de não percepções)? Neste trabalho, sustentar-se-á a primeira alternativa, a saber, que as representações sem consciência e suas divisões são também espécies de percepções.

Este ponto de vista encontra apoio na própria passagem em questão e em outras desta mesma obra, bem como em trechos da Antropologia e da Lógica. Com 
efeito, nesta passagem (CRPu, B376-7), pode-se dizer que, em linhas gerais, Kant compreende que as representações em geral são percepções, isto é, formas quaisquer de consciência (intelectual, sensível, pura, empírica, externa, interna, mediata, imediata) que acompanham toda atividade cognitiva, volitiva ou emotiva. Ademais, como, para Kant, toda "consciência (...) tem sempre um grau que pode ser ainda diminuído" (CRPu, B414-5), então, isso implica, de modo mais rigoroso, que as representações em geral são percepções acompanhadas de algum grau de consciência, ou, dito de modo equivalente, que as percepções são representações acompanhadas de um grau qualquer de consciência ${ }^{16}$.

O resultado da combinação destas duas passagens da CRPu é o de revelar que as duas principais divisões das representações em geral (Quadro 1) - a saber, as representações (1) com consciência e (10) sem consciência - constituem apenas dois graus limites de consciência sobre os quais pode incidir a reflexão filosófica. Porém, não são os únicos graus de consciência ou percepções possíveis. Na verdade, estes dois limites extremos de consciência - (1) e (10) - formam um intervalo preenchido por infinitos graus de consciência. Cada um destes infinitos graus de consciência é uma percepção, isto é, uma representação com determinado grau de consciência. O Quadro 1 ilustra apenas os dois graus de consciência ou percepções limites, os quais não se opõem enquanto uma presença total de consciência (1) e uma ausência absoluta de consciência (10), mas apenas um limite superior e inferior para as faculdades do sujeito. Além destes dois limites são igualmente possíveis graus (ou até mesmo níveis) de consciência, ad infinitum, porém, que extrapolam totalmente os limites das faculdades do sujeito, e que, por essa razão, nada significam para ele.

Embora este intervalo seja preenchido por infinitos graus de consciência, Kant mostra (Antr., Ak137-8) que é possível identificar nele três graus de consciência fundamentais: os dois graus extremos mencionados e um terceiro grau intermediário.

\footnotetext{
${ }^{16}$ Como explica Almeida (2013, p. 32), a "percepção, como sabemos, é um termo técnico kantiano que significa qualquer representação, mas, em particular, a intuição sensível, acompanhada de consciência (itálico acrescentado)". De modo mais preciso, tal como acima indicado, a percepção é qualquer representação acompanhada de algum grau de consciência.
} 
São eles assim nomeados por Kant: o grau da distinção, da clareza e do obscuro (o primeiro e o terceiro são os dois graus extremos e o segundo o grau intermediário). Tal como ocorre no Quadro 1, esta divisão tríplice dos graus de consciência é apenas ilustrativa, e de modo algum é exaustiva ou recobre toda a infinidade dos graus de consciência ou de percepção possível. Sua finalidade é apenas a de demarcar algumas referências principais para os graus de consciência, sem esgotá-los.

Admitida a hipótese de que as duas representações extremas do Quadro 1 (1) representações com consciência e (10) representações sem consciência - são espécies de percepções (isto é, representações com algum grau de consciência), resta a tarefa de denominá-las adequadamente ${ }^{17}$. Há duas alternativas possíveis em Kant, ambas plausíveis, embora com algumas ressalvas, porém a última delas parece ser a mais conveniente. A primeira consiste em chamar (1) de percepções claras e (10) de percepções obscuras. A segunda de denominar (1) de percepções distintas e (10) de percepções indistintas.

A primeira denominação segue uma sugestão da Antropologia (Ak137-8) em que Kant distingue em geral duas espécies de consciências fundamentais, as claras e as

\footnotetext{
${ }^{17}$ A designação atribuída por Kant às 'representações com consciência' é correta, mas pode ser desencaminhadora ao levar à interpretações equivocadas quanto às representações que the são opostas, a saber, as 'representações sem consciência'. Pois, através desta última expressão, se pode ser facilmente conduzido a pensar que estas últimas são desprovidas, de modo absoluto, de todo e qualquer grau de consciência ou percepção - o que não é verdade. Ao contrário, as representações 'sem' consciência são representações que têm sempre algum grau de consciência, pois, como disse Kant, acima, 'a consciência tem sempre um grau que pode ser ainda diminuído'. Portanto, os dois graus extremos das 'representações em geral' tem um grau de consciência, o qual é reduzido, de um lado, e elevado, de outro. Acresce-se a isso o fato referido no tópico 7 deste artigo - "Representações sem consciência em Kant e Locke" - que, de acordo com a concepção de Kant, as representações sem consciência estão sempre referenciadas a uma consciência formal, o Eu penso; pertencem, pois, sempre ao sujeito, não sendo necessário que este seja delas conscientes - isto é, o sujeito não precisa que tais representações sejam claras ou distintas, podem, pois, ser obscura ou indistintas. Conforme a hipótese levantada, elas já se encontram sobre uma 'primeira' consciência, de caráter puramente lógico, daí não haver a possibilidade de considerar uma total ausência de consciência, pois além dos graus de consciência sempre existentes - minimamente que seja -, ainda temos de nos reportar à existência de uma consciência formal, a qual todas as representações obrigatoriamente precisam referir-se: “(...) não há necessidade de que esse eu seja permanentemente consciente de toda e qualquer representação, para que essas representações sejam consideradas representações de um sujeito - tanto é assim que este pode não ser ou estar 'consciente delas como tais'. Basta, para tanto, que essa autoconsciência possa acompanhar tais representações" (GIACOIA, 2012, p. 104).
} 
obscuras, as quais podem ser associadas as duas consciências limites do Quadro 1, respectivamente, as representações com consciência e as representações sem consciência. Deste modo, haveria, analogamente, duas espécies fundamentais de percepção, as percepções claras e as percepções obscuras. O inconveniente desta interpretação é que, para Kant, o lado direito do Quadro 1 apresenta todas as partes das representações com consciência, o que configuraria este lado tratar-se das representações distintas, e não claras; todavia, desde que seja questionável se Kant atingiu o seu ideal de completude sistemática, então tal proposta torna-se justificável.

A segunda denominação resulta de uma sugestão da Lógica (Ak34-5), onde Kant diz que "todas as representações claras (...) podem ser diferenciadas com respeito à distinção e à indistinção (sic)". Ora, conforme a explicação acima, as representações claras equivalem justamente às representações intermediárias, as quais são situadas entre as representações limites do Quadro 1 - isto é, as representações (1) e (10). Portanto, esta passagem sugere que, analogamente, as representações extremas possam ser denominadas, respectivamente, de percepções distintas e percepções indistintas. A objeção a esta interpretação é que os exemplos dados por Kant, na referida passagem, indicam que ele entende aí por representações indistintas o que ele próprio chama, em outras obras (por exemplo, na Antropologia), de representações claras; todavia, se, nesta passagem da Lógica, conferir-se maior ênfase ao conceito, e não aos exemplos (vistos diferentemente por Kant em outas obras), então esta denominação é também justificável.

Doutor em Filosofia Professor do Programa de Pós-Graduação em Filosofia/UFPA E-mail: lued@ufpa.br 